\title{
The relationship between resilience and empowering leader behaviour of nurse managers in the mining healthcare sector
}

\begin{tabular}{|c|c|}
\hline $\begin{array}{l}\text { Authors: } \\
\text { Babalwa Tau } \\
\text { Emmerentia c } \\
\text { Daleen Koen }{ }^{2} \\
\text { Suria Ellis }{ }^{3}\end{array}$ & u Plessis 10 \\
\hline \multicolumn{2}{|c|}{$\begin{array}{l}\text { Affiliations: } \\
{ }^{1} \text { School of Nursing Science, } \\
\text { North-West University, } \\
\text { Potchefstroom, South Africa }\end{array}$} \\
\hline \multicolumn{2}{|c|}{$\begin{array}{l}{ }^{2} \text { School of Nursing Science, } \\
\text { North-West University, } \\
\text { Mafikeng, South Africa }\end{array}$} \\
\hline \multicolumn{2}{|c|}{$\begin{array}{l}\text { 3Unit for Business, } \\
\text { Mathematics and } \\
\text { Informatics, North-West } \\
\text { University, Potchefstroom, } \\
\text { South Africa }\end{array}$} \\
\hline \multicolumn{2}{|c|}{$\begin{array}{l}\text { Corresponding author: } \\
\text { Babalwa Tau, } \\
\text { 12023361@nwu.ac.za }\end{array}$} \\
\hline \multicolumn{2}{|c|}{$\begin{array}{l}\text { Received: } 05 \text { Dec. } 2017 \\
\text { Accepted: } 14 \text { May } 2018 \\
\text { Published: } 28 \text { June } 2018\end{array}$} \\
\hline \multicolumn{2}{|c|}{$\begin{array}{l}\text { How to cite this article: } \\
\text { Tau, B., Du Plessis, E., Koen, } \\
\text { D. \& Ellis, S., 2018, 'The } \\
\text { relationship between } \\
\text { resilience and empowering } \\
\text { leader behaviour of nurse } \\
\text { managers in the mining } \\
\text { healthcare sector', Curationis } \\
\text { 41(1), a1775. https://doi. } \\
\text { org/10.4102/curationis. } \\
\text { v41i1.1775 }\end{array}$} \\
\hline \multicolumn{2}{|c|}{$\begin{array}{l}\text { Copyright: } \\
\text { (C) 2018. The Authors. } \\
\text { Licensee: AOSIS. This } \\
\text { is licensed under the } \\
\text { Creative Commons } \\
\text { Attribution License. }\end{array}$} \\
\hline \multicolumn{2}{|l|}{ Read online: } \\
\hline  & $\begin{array}{l}\text { Scan this QR } \\
\text { code with your } \\
\text { smart phone or } \\
\text { mobile device } \\
\text { to read online. }\end{array}$ \\
\hline
\end{tabular}

Background: The South African mining healthcare sector faces injuries, illnesses including HIV and AIDS and high staff turnover rates. In this sector, nurse managers should create an optimal environment for providing nursing care by motivating, influencing and empowering nurses.

Objectives: This study aimed to investigate the relationship between nurse managers' resilience and empowering leader behaviour in this sector.

Method: The study employed a quantitative, descriptive and correlational design. The research population comprised 31 nurse managers, 101 professional nurses, 79 enrolled nurses and 79 enrolled nursing auxiliaries who participated in the study. Two questionnaires were used as data collection methods, namely Wagnild and Young's Resilience Scale Questionnaire to investigate the resilience of nurse managers and the Empowering Leadership Questionnaire to measure empowering leader behaviour of the nurses supervised by a particular nurse manager.

Results: Out of 31 nurse managers, 8 had a low level, 19 had a moderate level and 4 had a high level of resilience. According to Hoteling's $t$-test the nurse managers in the low resilience group displayed lower empowering leader behaviour as perceived by their team members than those in the high resilience group in terms of the five factors included in the Empowerment Leadership Questionnaire.

Conclusion: Respondents with high resilience scores tended to have higher leader empowering behaviour.

Recommendations include the strengthening of nurse managers' resilience through workshops and reflection practices, debriefing and performance feedback sessions.

\section{Introduction}

According to Nguyen et al. (2016:13) resilience is positioned in correlation to adversity - to demonstrate resilience, one must first encounter adversity, such as being a nurse leader in the mining healthcare sector required to cope with challenges. Allison (2012:79) in her research stated that in the presence of change and crisis, the resource needed most is resilience.

The question of whether resilience is associated with empowering leadership behaviour is of interest in this working environment. Resilient leadership is crucial in addressing complex issues associated with healthcare system challenges (Allison 2012:79; Jackson \& Daly 2011:21).

This article reports on a study that aimed to determine the resilience and empowering leadership behaviour of nurse managers in South Africa's mining healthcare sector. Understanding the level of resilience of nurse managers and knowing their level of leadership empowering behaviour and the relationship between these two enabled the formulation of a recommendation to strengthen the resilience of nurse managers.

\section{Background and literature review}

Although the gold mining sector brought many economic benefits to South Africa, there were also some social challenges (Stuckler et al. 2013:639). Stuckler et al. described the many challenges that the mining healthcare sector faces, including high levels of occupational injuries, illnesses and non-occupational diseases (such as HIV and AIDS) as well as high staff turnover rates. Moreover, the mining sector is characterised by a high level of occupational diseases such as silicosis and 
risks such as mine incidents. Mclaggan, Bezuidenhout and Botha (2013:1) stated that the mining industry is especially faced with challenges that include labour unrest, skills shortages, increased demand for productivity and high turnover. This places a great challenge on the mining healthcare sector, which renders services to the mining industry.

Nurses working in the mining healthcare sector have to carry the burden of providing nursing care to mine workers. This, in turn, leads to nurses being overworked and under pressure. These challenges have been associated with problems in retaining a viable nursing workforce (Jackson, Firtko \& Edenborough 2007:2).

Positive leadership qualities and strong facilitative leadership behaviour of first-line managers are therefore crucially important in creating an environment that increases job satisfaction and nurses' intention to stay (Sellgren, Ekvall \& Tomson 2008:584). According to Pillay (2011:176), nurse managers should take the lead in addressing challenges hampering the delivery of health services in the mining sector. Effective nurse leaders should be able to address complex issues associated with healthcare system changes to overcome the challenges they face (Bester, Stander \& Van Zyl 2015:1; MacPhee et al. 2011:159). Therefore, when facing these challenges, nurse managers in the mining healthcare sector have to display effective leadership skills.

Irrespective of the specific leadership styles and skills used, empowerment and sharing of power are innovative ways of encouraging all healthcare professionals to become involved in and committed to their work situation. Liu (2015:477) stated that empowering leadership behaviour is a series of management practices including participation and information sharing. Banutu-Gomez (2015:342) also stated that the role of leaders is to empower teams to successfully complete necessary leadership functions themselves.

Arnold et al. (2000:265) mentioned five categories of leadership behaviour constructs required for empowering teams, namely: (1) leading by example: as a set of behaviours displaying the commitment of the leader to his or her own work and that of the team, (2) coaching: behaviour that educates team members and assists them to become selfreliant, (3) showing concern: behaviour that shows a regard for team members' wellness, (4) informing: when the leader includes the team members in information pertaining to the vision and mission of the company and (5) participative decision-making: team members' inputs and information are considered by the leader, and team members are encouraged to express their opinions and ideas.

Similarly Kotzè et al. (2008:47) stated that effective leadership is a process of interaction where a leader influences others towards achieving a goal. Arnold et al. (2000:265) state that empowered teams have more autonomy, self-direction and control over their working environment. This produces job satisfaction, cost-effectiveness, better solutions and constructive conflict management (Maboko 2011:912). Effective leadership in adverse conditions - such as in the mining healthcare sector - can therefore be defined as:

competencies and processes required to enable and empower ordinary people to do extraordinary things in the face of adversity, and constantly turn into superior performance to the benefit of themselves. (Meyer et al. 2011:208)

Nurses' attitudes and work performance are affected by the leadership behaviour of nurse managers. Bester et al. (2015:11) agreed, stating that employees' perception of their leaders' empowering behaviour predicts intention to leave the organisation. It is therefore clear that nurse managers must develop empowering leadership skills, resilience, healthy relationships and conflict management skills while achieving productive goals. Moreover, given the high level of pressure, uncertainty and rapid changes accompanied by the challenges in the mining healthcare system it is evident that nurse managers need to be resilient (Rivers et al. 2011:48). According to Jackson and Daly (2011:21), resilient leaders not only have the ability to survive in difficulty and adversity but are able to display behaviour that will enhance subordinates' ability to thrive. They furthermore questioned the fact that concepts like adversity and resilience are seldom discussed in relation to nurse leaders, yet nurse leaders work in a context of great workplace difficulty.

Research linking resilience and leadership can be found (Harland et al. 2005:4; Nguyen et al. 2016:14). Harland et al. (2005:4) theorised on a link between leadership and resilience. These authors stated that developing the capacity for resilience is a vital component of effective leadership. Shahrazad et al. (2012:64) found significant correlations between leadership and resilience, namely the higher the skills of leadership, the higher the ability to be resilient and to overcome challenges.

\section{Problem statement}

Nguyen et al. (2016:13) in their study confirmed the findings of Harland et al. (2005:4) that the application of leadership to resilience has been largely ignored, and they suggested that such research should be undertaken. There seems to be a link between leadership and resilience, but currently the resilience and empowering leadership behaviour of nurse managers in the mining healthcare sector has not been explored. The fact that some nurse managers in the mining healthcare sector are able to cope with unexpected setbacks and overcome adversities and display effective leadership, as well as the fact that there might be a relationship between resilience and empowering leader behaviour (Shahrazad et al. 2012:64), prompted this investigation about the relationship between resilience and empowering leadership behaviour of nurse managers in the mining healthcare sector. The researchers were therefore interested in understanding how some nurse managers, as leaders, are able to overcome adversities and turn them into developmental experiences through empowering leadership behaviour. 


\section{Research objectives}

The objectives of this study were to:

- Determine the resilience of nurse managers in the mining healthcare sector.

- Determine the empowering leader behaviour of nurse managers in the mining healthcare sector as perceived by nurses working in teams with these managers.

- Determine the relationship between resilience and empowering leader behaviour of nurse managers in the mining healthcare sector.

\section{Definition of key concepts}

\section{Resilience}

Resilience is the personal qualities and skills that allow for an individual's healthy and successful functioning or adaptation within the context of significant adversity or a disruptive life event (Lee et al. 2013:269). According to Fiksel (2014:2) personal resilience is being resourceful and having a strong character. In this study resilience refers to the ability of the nurse managers in the mining healthcare sector to deal with adversity in the workplace.

\section{Empowering leader behaviour}

According to Hon and Chan (2013:199), empowering leader behaviour includes leading by example, coaching, showing concern, informing and participative decisionmaking. In this study empowering leader behaviour refers to the sharing of power of nurse managers with the view of enhancing employees' motivation and investment in their work

\section{Nurse manager}

A nurse manager is a nurse leader for a specific unit or area. In the mining healthcare sector the nurse manager manages the budget, medical records, employee performance evaluation, staff recruitment and retention, and he or she is also responsible for safety programmes.

\section{Mining healthcare sector}

A mining healthcare sector includes hospitals, primary healthcare clinics, biotechnology and a variety of medical products. The mining healthcare sector provides healthcare to people working in the mining industry and their families. This research focused on the mining healthcare sector in the North West and Gauteng provinces of South Africa.

\section{Contribution to the field}

Findings from this study inform us about the level of resilience of nurse managers and their level of leader empowering behaviour. Knowing the level of resilience of nurse managers enables us to strengthen the resilience of nurse managers and enables deeper probing into the concepts of resilience and leader empowering behaviour.

\section{Method \\ Research design}

A quantitative, descriptive and correlational design was used in this study.

\section{Context of the study}

This research was conducted in the South African operations of a mining group consisting of two hospitals, eight medical stations (also referred to as primary healthcare [PHC] clinics) and two occupational health centres. These healthcare facilities are situated in the North West and Gauteng provinces.

\section{Population and sampling}

In this research two groups were included. The population included 31 nurse managers as one group and 259 nurses working in teams with these nurse managers as the other group.

The first group comprised 31 nurse managers. The second group comprised professional nurses $(n=101)$, enrolled nurses $(n=79)$ and enrolled nurse auxiliaries $(n=79)$ registered and enrolled with South African Nursing Council working in the teams of the participating nurse managers.

An all-inclusive sampling technique was ideal because all members of these groups working in the specific mining healthcare sector where the research took place could be included.

\section{Research instruments}

The instruments used for data collection were self-administered questionnaires, which means that the respondents completed the instruments themselves (Polit \& Beck 2008:414). This study utilised two questionnaires as data collection methods, namely the Resilience Scale (RS) developed by Wagnild and Young (1993) and reviewed by Wagnild (2009) and the Empowering Leadership Questionnaire (ELQ) developed by Arnold et al. (2000).

The RS was completed by nurse managers $(n=31)$ and was used to collect data to determine their resilience. The questionnaire consists of 25 statements using a Likert scale ranging from 1 (strongly disagree) to 7 (strongly agree). The possible scores for the RS range from 25 to 175 . Scores greater than 160 indicated high resilience, scores between 145 and 160 indicated moderately high to high resilience levels, scores from 121 to 145 indicated moderately low to moderate resilience levels, and scores of 120 and below indicated low resilience levels. A Cronbach's alpha coefficient of 0.95 was obtained for this study.

The ELQ was used to collect data that determined the empowering leader behaviour of nurse managers in the mining healthcare sector. The questionnaire was completed by 259 nurses, who were supervised by the specific nurse managers who completed the RS. The questionnaire measures 
five factors of leadership behaviour for empowered teams. The five categories are leading by example, coaching, participative decision-making, informing, and showing concern and interacting with the team (Arnold et al. 2000:249). The questionnaire consists of 38 items. The questionnaire is a five-point response scale, where $1=$ 'never' and $5=$ 'always'.

\section{Data collection method}

Data for the study were collected during April 2015. The mediator, who was the health service manager for both healthcare facilities where data were collected, distributed questionnaires to 31 nurse managers and obtained informed consent. An information sheet describing the details of the study was also handed to the second group of respondents, nurses working in the teams of the nurse managers. Those who gave consent were then handed questionnaires. In order to ensure confidentiality, the respondents were requested not to include their names or any form of identification on the questionnaires. Respondents were allowed to complete the questionnaires at their own convenience.

\section{Data analysis}

Descriptive and inferential statistics were utilised to convert and condense the data into organised representations. The Statistical Package for the Social Sciences (SPSS) version 22 (2011) statistical program was used for data analysis and the guidelines from the 'Resilience Scale User's Guide' were also used (Wagnild 2011:72).

Correlations were calculated between the resilience of nurse managers using the RS questionnaire and the ELQ, taking into account the dependency between nurse managers and team members working with nurse managers. To examine this relationship further, nurse managers were categorised into groups of low, moderate and high resilience according to the guidelines of the developers. A multivariate Hoteling's $t$-test was performed to determine whether there was a statistical significant difference between the leadership subscale scores for nurse managers as perceived by their team members in low and high resilience categories.

\section{Ethical considerations}

Ethical approval was granted by the Health Research Ethics Committee of the North-West University (NWU), Potchefstroom Campus (NWU-00161-14-A1). Permission to access the mining healthcare sector and to conduct the study was obtained from the health service manager of the mining healthcare sector.

\section{Results Demographics}

All the nurse managers $(n=31)$ were females and their ages ranged between 38 and 53. The nurse managers were from both hospitals, which are urban hospitals.

Table 1 provides a breakdown of the number of nurse managers and teams working under each nurse manager's supervision specific units. In both hospitals (in both regions) the numbers were the same.

Medical stations are smaller than the hospitals; therefore the numbers were lower. On average for each nurse manager there were two $(n=2)$ professional nurses, one $(n=1)$ enrolled nurse and two $(n=2)$ enrolled nursing auxiliaries. Because of loss of confidentiality of respondents, no other demographic details were collected.

\section{Resilience of nurse managers}

The resilience questionnaire included five characteristics that consisted of 25 items. The means of the sub-scale scores of the RS are shown in Table 2. The first characteristic is purposeful life (meaning), the realisation that life has a purpose and the sense of having something for which to live; it had a mean of 28.2, which was the highest sub-score. Perseverance is the act of persistence despite adversity or discouragement, showing willingness to continue to reconstruct one's life and remain involved; it had a mean of 27.8. Self-reliance is a belief in oneself and in one's capabilities; it had a mean of 28.1 .

Existential aloneness, the realisation that a person's life path is unique, with a mean of 26.8 , had the lowest sub-score. Equanimity is a balanced perspective of one's life and experiences and it had a mean of 27.8 .

The average resilience score of all respondents was 138.5, indicating that this sample of nurse managers had a moderate level of resilience (see Table 2).

The results indicated that $25.8 \%(n=8)$ of the nurse managers had a low level of resilience of 120 or lower, $61.3 \%(n=19)$ had a moderate level of resilience, and $12.9 \%(n=4)$ had a high level of resilience, above 160 (see Table 3).

TABLE 1: Nurse managers and their teams in the mining healthcare sector. Nurse managers Professional nurses Enrolled nurses Enrolled nursing auxiliaries $n=31 \quad n=101 \quad n=79 \quad n=79$

TABLE 2: Resilience scale: Maximum and minimum scores, mean and standard deviation of the respondents

\begin{tabular}{lcccc}
\hline Variable & Cronbach's alpha & Minimum & Maximum & Mean \\
\hline Resilience & 0.953 & 88.00 & 168.00 & 138.53 \\
Purposeful life & 0.803 & 19.00 & 34.00 & 21.16 \\
Perseverance & 0.778 & 15.00 & 35.00 & 4.26 \\
Self-reliance & 0.805 & 17.00 & 35.00 & 27.77 \\
Existential aloneness & 0.826 & 12.00 & 35.00 & 28.06 \\
Equanimity & 0.648 & 18.00 & 32.00 & 26.77 \\
\hline
\end{tabular}




\section{Empowering leader behaviour of nurse managers}

The mean scores of the ELQ are shown in Table 4, where the average of all items contributing to the score was used to determine the sub-scale scores. This implies that the means can be interpreted on the original five-point Likert scale of measurement.

The mean for ELQ scale for leading by example, which had five items, was 3.89 (SD 0.982), indicating that managers are committed to their work as well as the work of team members. The mean of participative decision-making, which had six items, was 3.48 (SD 0.869), indicating that team members are of the opinion that managers are involving teams in decision-making. The mean for coaching, which loaded 11 items, was 3.70 (SD 0.977). This indicated that managers displayed behaviours that educated team members and helped them to become selfreliant. The mean for informing, which had six items, was 3.95 (SD 0.854), which was the highest and this indicated that the managers disseminated information such as mission and philosophy as well as other important information pertaining to the company. The mean for showing concern, which had 10 items, was 3.60 (SD 1.029), which indicated that managers demonstrated a general regard for team members' well-being (see Table 4). All these sub-scale scores were positive, with means larger than 3.5 .

TABLE 3: Summary of managers and nurse respondents in the managers' team, categorised by level of resilience of the manager.

\begin{tabular}{lccccc}
\hline \multirow{2}{*}{$\begin{array}{l}\text { Level of } \\
\text { resilience }\end{array}$} & \multicolumn{2}{c}{ Managers } & & \multicolumn{2}{c}{ Nurses in managers' team } \\
\cline { 2 - 3 } \cline { 6 - 7 } & Frequency & Percentage & & Frequency & Percentage \\
\hline $\begin{array}{l}\text { Low }(120 \text { or } \\
\text { below) }\end{array}$ & 8 & 25.8 & & 49 & 18.9 \\
Medium & 19 & 61.3 & & 173 & 66.6 \\
High (above 160) & 4 & 12.9 & & 37 & 14.3 \\
\hline Total & $\mathbf{3 1}$ & $\mathbf{1 0 0 . 0}$ & & $\mathbf{2 5 9}$ & $\mathbf{1 0 0 . 0}$ \\
\hline
\end{tabular}

\section{Relationship between resilience and empowering leader behaviour of nurse managers}

Three approaches were used to test the relationship between resilience and empowering leader behaviour. In the first approach, a correlation matrix was used to test the magnitude, direction and strength of the relationship between the variables. In the second approach, the univariate $t$-tests of independent groups was used to test the statistical significance between the means of each category of leader empowering behaviour as perceived by team members between high and low resilience managers. Thereafter a multivariate Hoteling's $t$-test was performed to determine whether there was a statistical significant difference between the leadership subscale scores for nurse managers as perceived by their team members in low and high resilience categories.

\section{Correlation results}

The correlation matrix representing the empowering leadership factors of the ELQ in relation to resilience is given in Table 5. No statistical or practically significant correlations of ELQ with resilience were found.

\section{Independent $t$-test results}

Seeing that no statistically significant correlations of ELQ with resilience were found when using a correlation matrix, to investigate this relationship further the $t$-test was used. The independent $t$-test was conducted between team members with managers in the low and high categories of resilience. This is a procedure used to test the statistical significance of a difference between the means of two groups.

Although the individual tests showed no statistical or practically significant differences between high and low resilience groups, all the ELQ scores in the high resilience group were higher than those in the lower group and a multivariate approach seemed to be viable.

TABLE 4: Reliability, mean and standard deviation of the Empowering Leadership Questionnaire.

\begin{tabular}{|c|c|c|c|c|c|}
\hline Variables & Cronbach's alpha & Minimum & Maximum & Mean & Standard deviation \\
\hline Leading by example & 0.935 & 1.00 & 5.00 & 3.90 & 0.98 \\
\hline Participative decision-making & 0.833 & 1.00 & 5.00 & 3.49 & 0.87 \\
\hline Coaching & 0.964 & 1.00 & 5.00 & 3.71 & 0.98 \\
\hline Informing & 0.930 & 1.00 & 5.00 & 3.95 & 0.85 \\
\hline Show concern & 0.963 & 1.00 & 5.00 & 3.61 & 1.03 \\
\hline
\end{tabular}

TABLE 5: Results of correlation between resilience and Empowering Leadership Questionnaire (ELQ) as well as Hoteling's $t$-test on ELQ sub-scores for high and low resilience groups.

\begin{tabular}{|c|c|c|c|c|}
\hline ELQ sub-factors & Correlation with resilience & Resilience group & Means & Standard deviation \\
\hline \multirow[t]{2}{*}{ Lead by example } & 0.006 & Low & 3.86 & 0.97 \\
\hline & - & High & 4.03 & 0.94 \\
\hline \multirow[t]{2}{*}{ Participative decision-making } & 0.055 & Low & 3.41 & 0.81 \\
\hline & - & High & 3.75 & 0.87 \\
\hline \multirow[t]{2}{*}{ Coaching } & 0.038 & Low & 3.61 & 1.01 \\
\hline & - & High & 3.90 & 1.06 \\
\hline \multirow[t]{2}{*}{ Informing } & 0.038 & Low & 3.84 & 0.90 \\
\hline & - & High & 3.98 & 0.88 \\
\hline \multirow[t]{2}{*}{ Showing concern } & 0.041 & Low & 3.49 & 1.01 \\
\hline & - & High & 3.80 & 1.04 \\
\hline
\end{tabular}

Note: Wilks' lambda $=0.077 ; p<0.001$. 


\section{Hoteling's $\boldsymbol{t}$-test results}

When Hoteling's $t$-test was performed on the ELQ scores, statistically significant differences between the low and high resilience groups showed statistically significant differences with Pillai's trace, Wilks's lambda, Hoteling's trace and Roy's largest root, indicating $p<0.001$. The generalised eta-squared effect size based on lambda for this multivariate test is 1 lambda $=1-0.077=0.923$, which indicates a large effect according to Steyn and Ellis (2009), where eta-squared of 0.02 is considered as a small effect, 0.13 as a medium effect and 0.26 as a large effect (see Table 5).

\section{Potential benefits and hazards}

The risk anticipated in this study was that managers could feel exposed if team members commented on their behaviour. The researcher therefore ensured anonymity and confidentiality by ensuring that no names would be used, only codes. All questionnaires were completed anonymously. The respondents did not receive any remuneration and there were no direct benefits for them.

\section{Recruitment procedures}

The researcher requested the health service manager to act as mediator. Recruitment was conducted by the health service manager, who was an independent person. The researcher organised a meeting with the permission of the health service manager, who was present at the meeting to explain the purpose of the research.

\section{Informed consent}

The nurse managers and their teams were informed about the purpose and nature of the study. The mediator obtained voluntary informed written consent from the prospective respondents. Respondents were given time to consider the invitation and were informed that they could withdraw at any time without incurring any risk to their well-being. The respondents were not coerced to participate in the study.

\section{Data protection}

Privacy was protected because respondents' names and information were kept confidential. No names of respondents were used in the research report. Codes were used in the research report to protect the identity of the respondents. The data would be destroyed after a period of seven years.

\section{Reliability}

Cronbach's alpha coefficients, based on inter-item correlations, were used to determine the reliability of the RS questionnaire. Cronbach's alpha tests the internal consistency of a measuring instrument (Botma et al. 2010:177). Both internationally and in South Africa the RS has demonstrated reliability, with alpha coefficients ranging from 0.85 to 0.94 . The RS was also used in the context of South Africa by Koen, Van Eeden and Wissing (2011:4) using 312 professional nurses employed in public and private hospitals and primary healthcare clinics, and a Cronbach's alpha coefficient of 0.95 was obtained. The Cronbach's alpha of the RS was 0.953, which indicated good internal consistency and reliability (see Table 2) (Wagnild 2009:106).

Arnold et al. (2000:249) in their article described the construction and validation of the ELQ. They evaluated the reliability of the ELQ in several organisations. The researchers concluded that the questionnaire indicated satisfactory reliability for all five ELQ sub-scales. The factors of the ELQ scale were divided into five categories of items and had a reliability exceeding 0.80 , which also indicated good internal consistency (see Table 4).

\section{Validity}

Validity for both questionnaires was tested. Validity referred to the questionnaires' ability to measure resilience and leadership amongst nurse managers in the mining healthcare sector and implied that the results could be applied to the larger community. The questionnaires were tested for content, face and construct validity.

The RS demonstrated content and construct validity in published studies (Black \& Ford-Gilboe 2004; Humphreys 2003; Monteith \& Ford-Gilboe 2002; Wagnild 2009). The construction of terms in the RS was those that reflect the generally acceptable definitions of resilience. Therefore the instrument was able to investigate the concept of resilience of nurse managers in the mining healthcare sector.

The construction of terms in the ELQ reflected generally acceptable definitions for empowered teams. The validity of the ELQ for this sample was tested by a confirmatory factor analysis, and it yielded satisfactory fit indices with a chisquare value divided by degrees of freedom (CMIN/df) of 2.59, a comparative fit index (CFI) of 0.904 and a root-meansquare error of approximation (RMSEA) of 0.078 with a $90 \%$ confidence interval $(0.074 ; 0.083)$. Because the chi-square test is viewed by some as an overly strict indicator of model fit, given its power to detect even trivial deviations from the proposed model (Hancock \& Mueller 2010), Mueller (1996) suggested that CMIN/df be used; interpretation of this value depends to a large extent on the viewpoint of the investigator, but in practice some interpret ratios as high as 3,4 or even 5 as still representing a good model fit (Mueller 1996). However, it is considered good practice to report multiple fit indices, typically from three broad classes (Hancock \& Mueller 2010). Mueller (1996) described values of above 0.9 as indicative of a good overall fit for a CFI. Blunch (2008) stated that models with RMSEA values of 0.10 and larger should not be accepted.

\section{Discussion}

\section{Resilience}

It is evident that this sample of nurse managers on average had a moderate level of resilience. Respondents felt especially proud of their achievements, and indicated that their life had meaning. Areas that might need attention relate to having a purposeful life, existential aloneness and equanimity (see Table 6). 


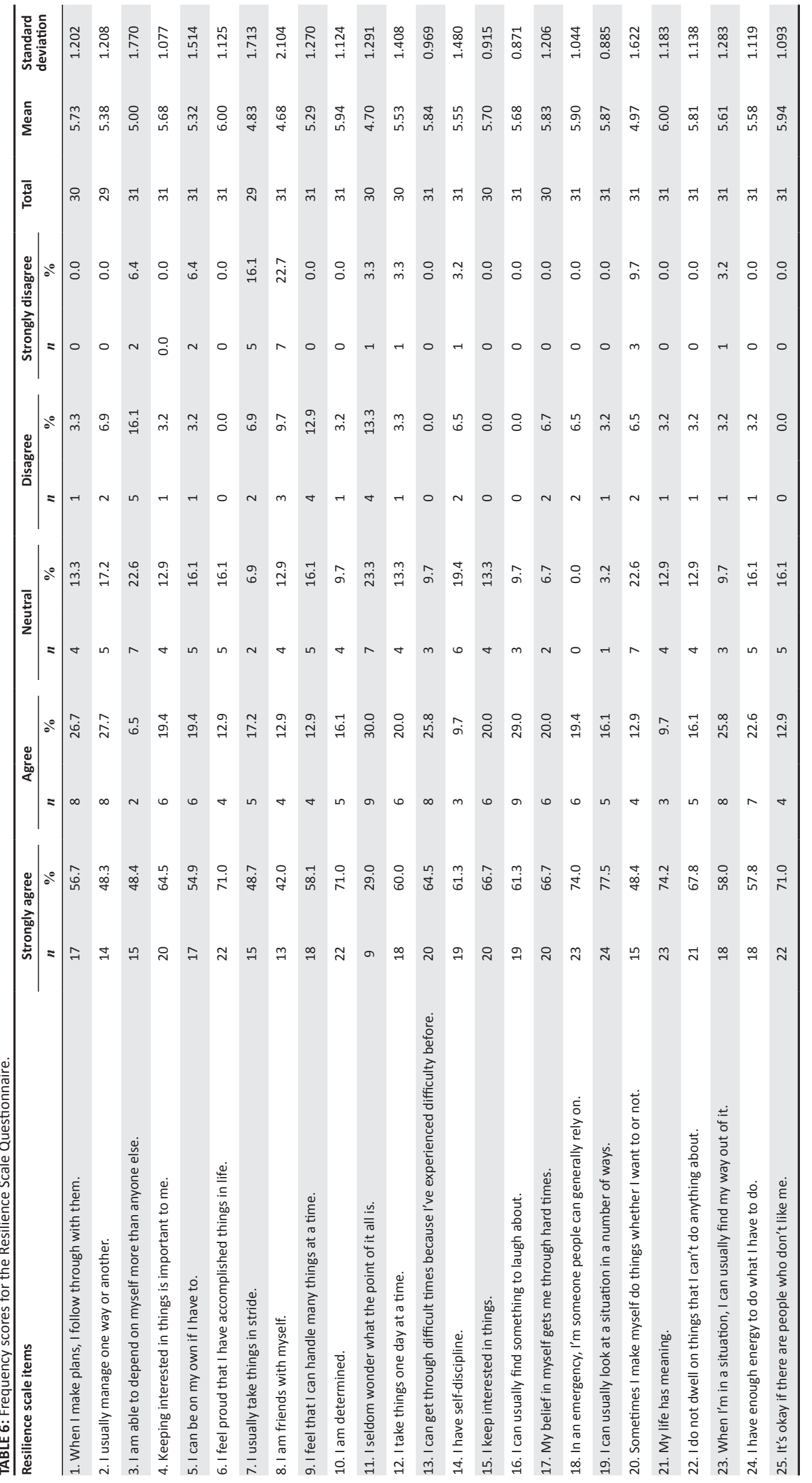


The first characteristic is purposeful life (meaning), defined by Wagnild and Young (1993) as the realisation that life has a purpose and the sense of having something for which to live. On average respondents in the mining healthcare sector agreed that they seldom wondered what the point of it all was. These results show that respondents felt proud that they had accomplished things in life.

Perseverance is the act of persistence despite adversity or discouragement; it shows willingness to continue to reconstruct one's life and remain involved. According to these results, respondents agreed that when they made plans, they followed through with them. It was further evident that most respondents were determined and had selfdiscipline. Results showed that the majority of respondents sometimes made themselves do things whether they wanted to or not.

Self-reliance is a belief in oneself and in one's capabilities. It is the ability to depend on oneself and recognise limitations and personal strengths. This indicates that respondents agreed that they were able to manage one way or another.

Existential aloneness is the realisation that a person's life path is unique. It confers a feeling of freedom and sense of uniqueness and had the lowest sub-scale score. This finding is an indication that the mining healthcare sector should be aware that some nurse managers might need guidance with regard to existential aloneness, and these respondents therefore may need to strengthen their resilience.

Research has shown that leaders need to be resilient in order to lead their teams. According to Jackson and Daly (2011:21), resilient leaders not only have the ability to survive in difficulty and adversity but are able to display behaviour that will enhance subordinates' ability to thrive. According to Koen et al. (2011:114), registered nurses show enabling strengths that facilitate resilience in difficult workplace circumstances, and this was also seen with the nurse managers in this research. Moran and Tame (2012:233) confirmed that for organisations to adapt, individuals must work towards a resilient culture. Resilient nurse managers are able to survive and thrive in a context of workplace difficulty, and this will also influence the nurses' ability to survive and thrive.

\section{Empowering leadership behaviour}

Most nurses felt that nurse managers displayed empowering behaviour, were leading by example and empowered team members through coaching. With regard to participative decision-making, nurse managers used team members' information and inputs. Furthermore, most nurses felt that the nurse managers encouraged team members to express ideas and that the nurse managers showed concern and cared about the group members' personal problems and well-being (see Table 7).
Germain and Cummings (2010:433) suggested that nurses feel empowered when their nurse leaders show confidence in their abilities to perform. They furthermore stated that when nurses feel important by being able to make decisions, without seeking approval from their leaders, they feel empowered to perform. This produces job satisfaction, cost-effectiveness, better solutions and constructive conflict management. A number of researchers proposed that to manage changes and challenges in the healthcare system, nurse managers must move away from the traditional management paradigm of hierarchal power and control to a model of leadership that shares power and control (Bester et al. 2015; De Klerk \& Stander 2014; Tomey 2009; Zhang \& Bartol 2010).

\section{Relationship between resilience and empowering leader behaviour}

Hoteling's $t$-test showed a statistically significant relationship, where nurse managers with high resilience levels were perceived by team members to have statistically higher empowering leadership scores than managers with low resilience levels.

\section{Limitations of the study}

The study was limited to one mining healthcare sector. The results of the study can thus not be generalised.

Data collection involved only the respondents' selfcompletion of questionnaires. In-depth individual and focus group discussions with nurse managers and with the nurses of different categories could have produced more in-depth information.

\section{Recommendations \\ Recommendations for nursing practice}

Nurse managers should attend workshops and in-service training on strengthening resilience to handle adverse working conditions in the mining healthcare sector. Nurse managers must attend leadership development programmes, specifically leadership coaching, to prepare managers for coping with healthcare challenges. Factors such as informing and leading by example have to be included in leadership development programmes.

\section{Recommendation for future research}

Research should be conducted to further explore the relationship between resilience and empowering leader behaviour of nurse managers in the mining healthcare sector of South Africa. Future studies should consider qualitative methods.

\section{Conclusion}

It is clear that higher leadership qualities are related to higher resilience levels. The value of this study is that it has given attention to the under-investigated issue of resilience and 


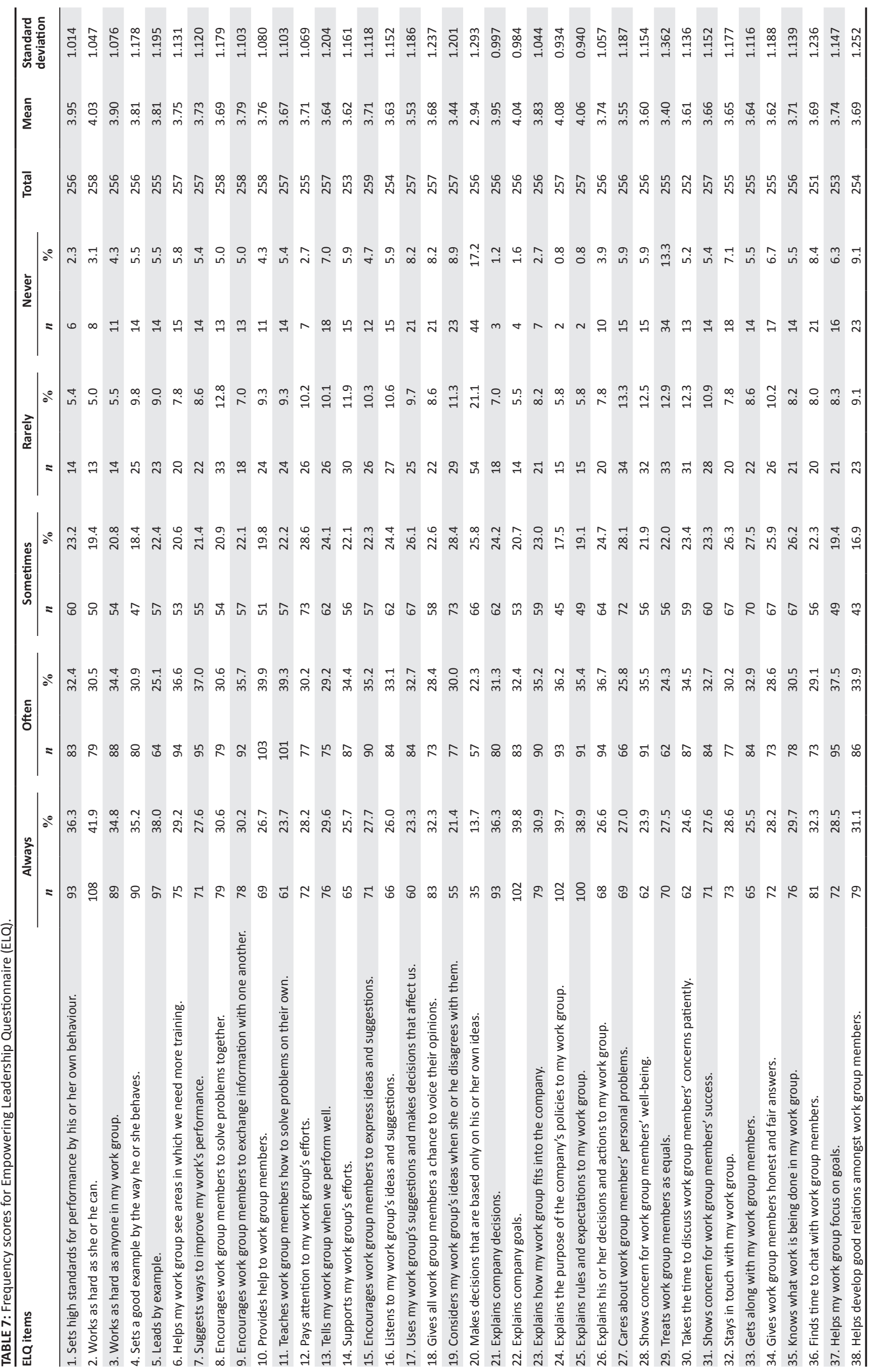


empowering leadership behaviour in South Africa's mining healthcare sector.

\section{Acknowledgements}

We wish to thank the relevant mining healthcare sector for granting permission for this study. We would like to thank all the nurse managers and nurses who participated in the study by completing questionnaires.

\section{Competing interests}

The authors declare that they have no financial or personal relationships that may have inappropriately influenced them in writing this article.

\section{Authors' contributions}

B.T. collected the data and wrote the initial draft. E.d.P., D.K. and S.E. were the supervisors of the research project and rendered inputs throughout all stages of the study. They revised and edited the draft.

\section{References}

Allison, E., 2012, 'The resilient leader', The Resourceful School 69(4), 79-82.

Arnold, J.A., Arad, S., Rhoades, J.A. \& Drasgow, F., 2000, 'The empowering leadership questionnaire: The construction and validation of a new scale for measuring leader behaviours', Journal of Organizational Behaviour 21(3), 249-269. https:// doi.org/10.1002/(SICI)1099-1379(200005)21:3<249::AID-JOB10>3.0.CO;2-\#

Banutu-Gomez, M.B., 2015, 'Understanding leadership and empowerment in the workplace', European Scientific Journal 35(11), 342-365.

Bester, J., Stander, M.W. \& Van Zyl, L.E., 2015, 'Leadership empowering behaviour, psychological empowerment, organisational citizenship behaviours and turnover intention in a manufacturing division', SA Journal of Industrial Psychology 41(1) 1-14. https://doi.org/10.4102/sajip.v41i1.1215

Black, C. \& Ford-Gilboe, M., 2004, 'Adolescent mothers: Resilience, family health work and health promoting practices', Journal of Advanced Nursing 48(4), 351-360.

Blunch, N.J., 2008, Introduction to structural equation modelling using SPSS and AMOS, Sage, London.

Botma, Y., Greeff, M. Mulaudzi, F.M. \& Wright, S.C.D., 2010, Research in health sciences, Heinemann Pearson, Cape Town.

De Klerk, S. \& Stander, W.M., 2014, 'Leadership empowerment behaviour, work engagement and turnover intention: The role of psychological empowerment', Journal of Positive Management 5(3), 28-45. https://doi.org/10.12775/JPM.2014.018

Fiksel, J., 2014, 'Why resilience', Journal of Resilience, viewed 28 November 2015,

from www.resilience.org/stories/2014-10-29/why-resilience

Germain, P.B. \& Cummings, G.G., 2010, 'The influence of nursing leadership on nurses' performance: A systematic literature review', Journal of Nursing Management 18(4), 425-439. https://doi.org/10.1111/j.1365-2834.2010.01100.x

Hancock, G.R. \& Mueller, R.O., 2010, The reviewer's guide to quantitative methods in the social sciences, Routledge, New York, NY.

Harland, L., Harrison, W., Jones, J.R. \& Palmon, R.R., 2005, 'Leadership behaviours and subordinate resilience', Journal of Leadership and Organizational Studies 11(2), 2-14. https://doi.org/10.1177/107179190501100202

Hon, A.H.Y. \& Chan, W.W.H., 2013, 'Team creative performance: The roles of empowering leadership, creative-related motivation, and task interdependence', Cornell Hospitality Quarterly 54(2), 199-210. https://doi.org/10.1177/1938965512455859

Humphreys, J., 2003, 'Research in sheltered battered women', Issues in Mental Health Nursing 24, 137-152.

Jackson, D. \& Daly, J., 2011, 'All things to all people: Adversity and resilience in leadership', Nurse Leader 9(3), 21-22, 30. https://doi.org/10.1016/j.mnl.2011.03.003

Jackson, D., Firtko, A. \& Edenborough, M., 2007, 'Personal resilience as a strategy for surviving and thriving in the face of workplace adversity: A literature review', Journal of Advanced Nursing 60(1), 1-9. https://doi.org/10.1111/j.1365-2648.2007.04412.x https://doi.org/10.1111/j.1365-2834.2011.01342.x
Koen, M.P., Van Eeden, C. \& Wissing, M.P., 2011, 'The prevalence of resilience in a group of professional nurses', Health SA Gesondheid 1(16), 1-11. https://doi. group of professional nurses',
org/10.4102/hsag.v16i1.576

Kotzè, W., Armstrong, S., Geyer, N., Mngomezulu, T., Potgieter, E. \& Subedar, H., 2008, Nurse educators' guide to management, Van Schaik Publishers, Potchefstroom.

Lee, H.J., Nam, S.K., Kim, A.R., Kim, B., Lee, M.Y. \& Lee, S.M., 2013, 'Resilience: A metaanalytic approach', Journal of Counselling \& Development 91(3), 269-279. https:// doi.org/10.1002/j.1556-6676.2013.00095.x

Liu, Y., 2015, 'The review of empowerment leadership', Open Journal of Business and Management 5, 476-482.

Maboko, D.R., 2011, 'Nursing leadership in an academic hospital in Gauteng', Journa of Nursing Management 20(7), 912-920. https://doi.org/10.1111/j.1365 2834.2011.01336.x

MacPhee, M., Skelton-Green, J., Bothillette, F. \& Suryaprakash, N., 2011, 'An empowerment framework for nursing leadership development: Supporting evidence', Journal of Advanced Nursing 68(1), 159-169. https://doi.org/10.1111/ j.1365-2648.2011.05746.x

Mclaggan, E., Bezuidenhout, A. \& Botha, C.T., 2013, 'Leadership style and organizational commitment in the mining industry in Mpumalanga', SA Journal of Human Resource Management 11(1), 1-9. https://doi.org/10.4102/sajhrm. v11i1.483

Meyer, S.M., Naudé, M., Shangase, N.C. \& van Niekerk, S.E., 2011, The nursing unit manager: A comprehensive guide, 3rd edn., Heinemann, Sandton.

Monteith, B. \& Ford-Gilboe, M., 2002, 'The relationship among mother's resilience, family health work, and mother's health promoting lifestyle practices in families with pre-school children', Journal of Family Nursing 8(4), 383-407.

Moran, B. \& Tame, P., 2012, 'Organizational resilience: Uniting leadership and enhancing sustainability. Research and solutions. Sustainability', The Journal of Record 5(4), 233-237.

Mueller, R.O., 1996, Basic principles of structural equation modeling: An introduction to LISREL and EQS, Springer, New York, NY.

Nguyen, Q., Kuntz, J.R.C, Naswall, K. \& Malinen, S., 2016, 'Employee resilience and leadership styles: The moderating role of proactive personality and optimism' New Zealand Journal of Psychology 45(2), 13-21.

Pillay, R., 2011, 'The skills gap in nursing management in the South African public health sector', Public Health Nursing 28(2), 176-185. https://doi.org/10.1111/ j.1525-1446.2010.00910.x

Polit, D.F. \& Beck, C.T., 2008, Nursing research: Generating and assessing evidence for nursing practice, 8th edn., Wolters Kluwer, Lippincott Williams \& Wilkins, Philadelphia.

Rivers, R., Pesata, V., Beasley, M. \& Dietrich, M., 2011, 'Transformational leadership: Creating a prosperity-planning coaching model for RN retention'. Nurse Leader 9(5), 48-51. https://doi.org/10.1016/j.mnl.2011.01.013

Sellgren, S.F., Ekvall, G. \& Tomson, G., 2008, 'Leadership behaviour of nurse managers in relation to job satisfaction and work climate', Journal of Nursing Management 16(5), 578-587. https://doi.org/10.1111/j.1365-2934.2007.00837.x

Shahrazad, W.S., Fauziah, I., Asmah Bee, M.N. \& Ismail, B., 2012, 'A cooperative study of self-esteem, leadership and resilience amongst illegal motorbike racers and normal adolescents in Malaysia', Asian Social Science 8(8), 61-68. https://doi. org/10.5539/ass.v8n8p61

SPSS Inc, 2011, IBM SPSS Statistics Version 22, Release 22.0.0, Copyright@ IBM Corporation and its licensors, viewed 07 October 2014, from http://www-01.ibm. com/software/analytics/spss/

Steyn, H.S. Jr. \& Ellis, S.M., 2009, 'Estimating an effect size in one-way multivariate analysis of variance (MANOVA)', Multivariate Behavioural Research 44, 106-129. https://doi.org/10.1080/00273170802620238

Stuckler, D., Steele, S., Lurie, M. \& Basu, S., 2013, 'Dying for gold: The effects of mineral mining on HIV, tuberculosis, silicosis and occupational disease in Southern Africa', International Journal of Health Services 43(4), 639-649. https://doi. org/10.2190/HS.43.4.C

Tomey, A.M., 2009, 'Nursing leadership and management effects work environments', Journal of Nursing Management 17(1), 15-25. https://doi.org/10.1111/j.13652834.2008.00963.x

Wagnild, G., 2009, 'A review of the resilience scale', Journal of Nursing Measurement 17(2), 105-113. https://doi.org/10.1891/1061-3749.17.2.105

Wagnild, G.M., 2011, The Resilience Scale user's guide for the US English version of the Resilience Scale and the 14-item Resilience Scale (RS-14), Resilience Center, Worden, Mont.

Wagnild, G.M. \& Young, H.M., 1993, 'Development and psychometric evaluation of the resilience scale', Journal of Nursing Measurement 1(2), 165-178.

Zhang, X. \& Bartol, K.M., 2010, 'Linking empowering leadership and employee creativity: The influence of psychological empowerment, intrinsic motivation and creative process engagement', Academy of Management Journal 53(1), 107-128. https://doi.org/10.5465/amj.2010.48037118 